\title{
Sequentially administrated of pemetrexed with icotinib/erlotinib in lung adenocarcinoma cell lines in vitro
}

\author{
Xiuli Feng ${ }^{1,2, *}$, Yan Zhang ${ }^{1,3, *}$, Tao $\mathbf{L i}^{1}$ and $\mathbf{Y u ~ L i}{ }^{1}$ \\ ${ }^{1}$ Department of Respiratory Medicine, Qilu Hospital of Shandong University, Jinan, Shandong 250012, China \\ ${ }^{2}$ Department of Respiratory Medicine, People's Hospital of Qingzhou, Weifang, Shandong 262500, China \\ ${ }^{3}$ The Fourth People's Hospital of Jinan, Jinan, Shandong 250031, China \\ "These authors have contributed equally to this work \\ Correspondence to: Yu Li, email: liyu796@163.com
}

Keywords: Iung adenocarcinoma; sequence; chemotherapy

Received: April 20, $2017 \quad$ Accepted: October 03, $2017 \quad$ Published: December 14, 2017

Copyright: Feng et al. This is an open-access article distributed under the terms of the Creative Commons Attribution License 3.0 (CC BY 3.0), which permits unrestricted use, distribution, and reproduction in any medium, provided the original author and source are credited.

\section{ABSTRACT}

Combination of chemotherapy and epidermal growth factor receptor-tyrosine kinase inhibitors (EGFR-TKIs) had been proved to be a potent anti-drug for the treatment of tumors. However, survival time was not extended for the patients with lung adenocarcinoma (AdC) compared with first-line chemotherapy. In the present study, we attempt to assess the optimal schedule of the combined administration of pemetrexed and icotinib/erlotinib in AdC cell lines. Human lung AdC cell lines with wild-type (A549), EGFR T790M (H1975) and activating EGFR mutation (HCC827) were applied in vitro to assess the differential efficacy of various sequential regimens on cell viability, cell apoptosis and cell cycle distribution. The results suggested that the antiproliferative effect of the sequence of pemetrexed followed by icotinib/ erlotinib was more effective than that of icotinib/erlotinib followed by pemetrexed. Additionally, a reduction of $\mathbf{G 1}$ phase and increased $S$ phase in sequence of pemetrexed followed by icotinib/erlotinib was also observed, promoting cell apoptosis. Thus, the sequential administration of pemetrexed followed by icotinib/erlotinib exerted a synergistic effect on HCC827 and H1975 cell lines compared with the reverse sequence. The sequential treatment of pemetrexed followed by icotinib/erlotinib has been demonstrated promising results. This treatment strategy warrants further confirmation in patients with advanced lung AdC.

\section{INTRODUCTION}

As a life-threatening malignancy, advanced-stage non-small-cell lung cancer (NSCLC) is responsible for $17 \%$ of the total new cancer cases and $23 \%$ of the total cancer deaths, and accounts for approximately $87 \%$ of lung cancer cases [1]. Adenocarcinoma (AdC) is the most frequent subtype and rates continue to increase in most populations [2]. There exists broad evidence base supporting the administration of platinum-based combination chemotherapy has been a first-line treatment for advanced NSCLC for years [3, 4]. However, platinum- based chemotherapy leads to more gastrointestinal, neuroor nephrotoxicity, while bone marrow toxicity is more common with carboplatin [5]. Pemetrexed, a treatment option for patients with advanced non-squamous NSCLC, had no significant differences in efficacy and safety compared with other chemotherapy options in second line treatment. It should be reasonable to optimize its use, since pemetrexed is relatively less toxic and currently used as continuation maintenance therapy for longer period, and the high budgetary impact of its incorporation into health system is of concern. Thus, optimum regimen of pemetrexed in the treatment of NSCLC should be investigated [6]. 
For patients with lung AdC harbouring activating epidermal growth factor receptor (EGFR) mutations, EGFR-tyrosine kinase inhibitors (EGFR-TKIs) has become the most effective first-line treatment. However, EGFR-TKI monotherapy is limited and further investigation to prolong the progression-free survival (PFS) is urgently needed. A Phase II clinical trial demonstrated that combination of pemetrexed and gefitinib was more prominent in improving PFS compared with gefitinib alone in patients with advanced nonsquamous NSCLC and activating EGFR mutations [7]. Pemetrexed was sequentially administered with gefitinib was proved to prolong a significant PFS and could be well-tolerated in advanced NSCLC patients with activation EGFR mutations [8]. In addition, a published trial conducted by Yi-Long $\mathrm{Wu}$ [9] confirmed that sequence of paclitaxel followed by gefitinib was an appropriate treatment regimen for AdC patients with activating EGFR mutation, indicating that the sequence of chemotherapy plus EGFR-TKIs might improve their efficacy. Although the combination of EGFR-TKIs and chemotherapy is a promising method for treating advanced $\mathrm{AdC}$, the cell cycle-associated antagonistic effect is observed between EGFR-TKIs and chemotherapy [10]. It is largely due to inappropriate drug administration sequences for the negative benefits. Therefore, there is a pressing need to develop effective and viable therapeutic strategies to enhance the anti-tumor activity and prolong the survival time.

In the present study, we therefore selected the lung AdC A549 (wild-type), HCC827 (EGFR exon19 deletions), and H1975 (EGFR T790M) to investigate the treatment effects of pemetrexed, icotinib and erlotinib in different sequential schedules on cell growth proliferation, apoptosis and cell cycle distribution. Our findings may provide a meaningful insight to clinical medication.

\section{RESULTS}

\section{Drug sensitivities of the A549, HCC827 and H1975 cell lines}

To investigate the sensitivities of 3 drugs, A549, HCC827 and H1975 were exposed to pemetrexed, icotinib or erlotinib for $72 \mathrm{~h}$. Pemetrexed, icotinib or erlotinib inhibited AdC cell growth in a dose-dependent after $72 \mathrm{~h}$ treatment alone. Table 1 summarizes the IC50 of pemetrexed, icotinib and erlotinib. The sensitivity of A549, HCC827 and H1975 cell lines to pemetrexed was similar. The HCC827 cell line had great sensitivity to icotinib and erlotinib.

\section{Effects of pemetrexed, icotinib and erlotinib on cell viability}

Further, the cell viability of these three cell lines in three different sequences was determined using an
CCK-8 assay to evaluate the antiproliferative effects of pemetrexed in combination with icotinib and erlotinib. Figure 1A showed the schema for in vitro sequential administration of icotinib/erlotinib and pemetrexed. As shown in Figure 1B, pemetrexed and icotinib/ erlotinib have sequence-dependent antiproliferative effects. Although the differences were not significant, a superior antiproliferative effect was observed in the sequence of pemetrexed followed by icotinib/erlotinib than other sequences in the A549, HCC827 and H1975 cell lines.

The combined effects between pemetrexed and icotinib/erlotinib were determined by combination index (CI) analysis (Table 2). In the HCC827 and H1975 cell lines, the sequence of pemetrexed followed by icotinib/ erlotinib exhibited a synergistic antiproliferative effect $(\mathrm{CI}<1)$, while $\mathrm{CI}>1$ represented antagonistic effects in the sequence of icotinib/erlotinib followed by pemetrexed and the concomitant treatment $(\mathrm{CI}>1)$. By contrast, in A549 cell line, antagonistic activity was observed in the sequence of pemetrexed followed by icotinib/erlotinib and the reverse sequence $(\mathrm{CI}>1)$.

\section{Effects of pemetrexed, icotinib and erlotinib on cell apoptosis}

After being exposed to pemetrexed, icotinib and erlotinib at the IC 50 values, the proportions of apoptotic cells were analyzed in Figure 2. In A549, HCC827 and H1975 cell lines, the apoptotic proportions induced by pemetrexed followed by icotinib were $6.36 \pm 0.65$, $30.22 \pm 7.97$ and $18.22 \pm 5.09$, respectively. The apoptotic proportions in A549, HCC827 and H1975 cell lines caused by pemetrexed followed by erlotinib were $5.26 \pm 0.3$, $50.47 \pm 8.68,20.1 \pm 4.07$. The apoptotic proportion in HCC827 and H1975 cell lines treated with pemetrexed followed by icotinib/erlotinib was significantly higher than other administration regimens in HCC827 and H1975 cell lines; however, there was no significant difference in A549 cell line.

\section{Effects of pemetrexed, icotinib and erlotinib on the cell cycle distribution}

The effect on the cell cycle distribution was shown in Figure 3. In response to the sequence of pemetrexed followed by icotinib, cell fractions in the $\mathrm{S}$ phase were increased whereas those in the G1 or G2 phase were decreased compared with control group in A549, HCC827 and H1975 cell lines. As for the sequence of pemetrexed followed by erlotinib, cell fractions in the $\mathrm{S}$ phase were elevated $(43.37 \pm 0.69,49.26 \pm 2.96$ and $44.05 \pm 2.93)$ while those in the G1 or G2 phase were reduced in A549, HCC827 and H1975 cell lines. However, decreased S phase and elevated G1 or G2 phase were found in the reverse sequence in three cell lines. 
Table 1: $\mathrm{IC}_{50}$ values for each drug were calculated by performing dose-response experiments with pemetrexed, icotinib and erlotinib

\begin{tabular}{lccc}
\hline Cell lines & Pemetrexed $(\boldsymbol{\mu m o l} / \mathbf{L})$ & Icotinib $(\boldsymbol{\mu m o l} / \mathbf{L})$ & Erlotinib $(\boldsymbol{\mu m o l} / \mathbf{L})$ \\
\hline A549 & $1.900 \pm 0.204$ & $7.727 \pm 0.809$ & $6.664 \pm 0.340$ \\
HCC827 & $1.578 \pm 0.250$ & $0.004 \pm 0.001$ & $0.003 \pm 0.001$ \\
H1975 & $3.372 \pm 0.082$ & $5.798 \pm 0.998$ & $4.812 \pm 0.0576$ \\
\hline
\end{tabular}

Table 2: Combination index (CI) values

\begin{tabular}{lcccccc}
\hline CI & P+I & P-I & I-P & P+E & P-E & E-P \\
\hline A549 & $1.46 \pm 0.22$ & $1.00 \pm 0.06$ & $1.00 \pm 0.08$ & $1.29 \pm 0.05$ & $1.00 \pm 0.09$ & $1.02 \pm 0.06$ \\
HCC827 & $1.30 \pm 0.20$ & $0.67 \pm 0.12$ & $1.04 \pm 0.18$ & $1.37 \pm 0.41$ & $0.68 \pm 0.12$ & $1.00 \pm 0.11$ \\
H1975 & $1.20 \pm 0.15$ & $0.61 \pm 0.07$ & $1.03 \pm 0.14$ & $1.27 \pm 0.08$ & $0.72 \pm 0.03$ & $1.00 \pm 0.05$ \\
\hline
\end{tabular}

C, control group; P, pemetrexed; I, icotinib; E, erlotinib; P-I/E, pemetrexed followed by icotinib/erlotinib; I/E-P, icotinib/ erlotinib followed by pemetrexed; $\mathrm{P}+\mathrm{I} / \mathrm{E}$, pemetrexed plus icotinib/erlotinib.

\section{DISCUSSION}

In this present study, we conducted in vitro experiment to explore the optimal sequential administration of pemetrexed and icotinib/erlotinib in lung AdC A549 (EGFR wild-type), HCC827 (EGFR exon19 deletions), and H1975 (EGFR T790M) cell lines. The results showed that the antiproliferative effect of the sequence of pemetrexed followed by icotinib or erlotinib was more prominent than that of icotinib/erlotinib followed by pemetrexed. In addition, the treatment of pemetrexed followed by icotinib/erlotinib produced a synergistic effect on HCC827, H1975 cell lines. Our findings suggest that the sequential strategy is a promising approach to treat advanced lung adenocarcinoma.

EGFR-TKI combined with chemotherapy as a new strategy has become a hot research topic in the treatment of lung cancer $[11,12]$. Recently, sequential regimens have attracted more interests in NSCLC researches. Fiala $\mathrm{O}$ et al [13] evaluated the effect of second-line pemetrexed with third-line erlotinib on advanced-stage (IIIB/IV) lung cancer with wild-type EGFR gene, indicating significant improvement of both PFS and overall survival for patients sequentially treated with erlotinib and pemetrexed compared with the pemetrexederlotinib sequence. A clinical retrospective study carried out by Zheng Y et al [14] demonstrated that the sequence of first-line pemetrexed followed by icotinib is promising for advanced lung cancer harboring unknown EGFR gene in China. These studies support the use of EGFRTKIs in the second-line setting in advanced lung AdC. In the present study, sequential therapy of pemetrexed followed by icotinib/erlotinib leads to a synergistic effect on HCC827 and H1975 cell lines which is comparable to the reverse sequence of icotinib or erlotinib followed by pemetrexed.
As indicated in clinical practice, the EGFR-TKIs are recommended as first-line regimen in patients with advanced lung AdC harboring EGFR mutations. However, IPASS [15] and OPTIMAL [16] clinical trials suggested that patients with NSCLC received EGFR-TKIs alone failed to prolonged progression-free survival (PFS), and showed secondary resistance after 10-13 months in 1013 months with objective response rate (ORR) of $43 \%$ in IPASS and $83 \%$ in OPTIMAL. In order to improve the PFS and the efficacy, JMIT study of Cheng Y found that gefitinib synchronized with pemetrexed could significantly extend PFS [7]. The FASTACT-2 study, presented by Professor Yilong $\mathrm{Wu}$, showed that alternative therapy of chemotherapy and erlotinib obviously prolonged PFS and OS in patients with advanced NSCLC, especially in patients with EGFR mutations, PFS could be up to 16.8 months [17]. While, H Yan et al [18] demonstrated that concurrent chemotherapy with EGFR-TKIs was not superior to single chemotherapy or EGFR targeted therapy.

The antagonistic action between EGFR-TKI and chemotherapy seems most likely to contribute to explain these negative results. Mahaffey C M [19] performed the sequence of docetaxel followed by erlotinib in A549 and Calu-1 cell lines. The significantly enhanced apoptosis was observed compared with the reverse sequence of erlotinib followed by docetaxel, thus they hypothesized there was a negative interaction between chemotherapy and EGFR TKIs, and cell cycle arrest induced by erlotinib in the presence of wild-type EGFR accounts for the lack of benefit. An in vitro study performed by Cheng $\mathrm{H}$ et al [20] investigating differential effects of various sequences of paclitaxel with gefitinib on lung cancer cell lines with activating EGFR mutation, revealed that the sequence of paclitaxel followed by gefitinib arrested cells in $\mathrm{G} 1$, whereas the reverse sequence arrested cells in $\mathrm{S}$ and $\mathrm{G} 2$ phases. Moreover, it was reported 


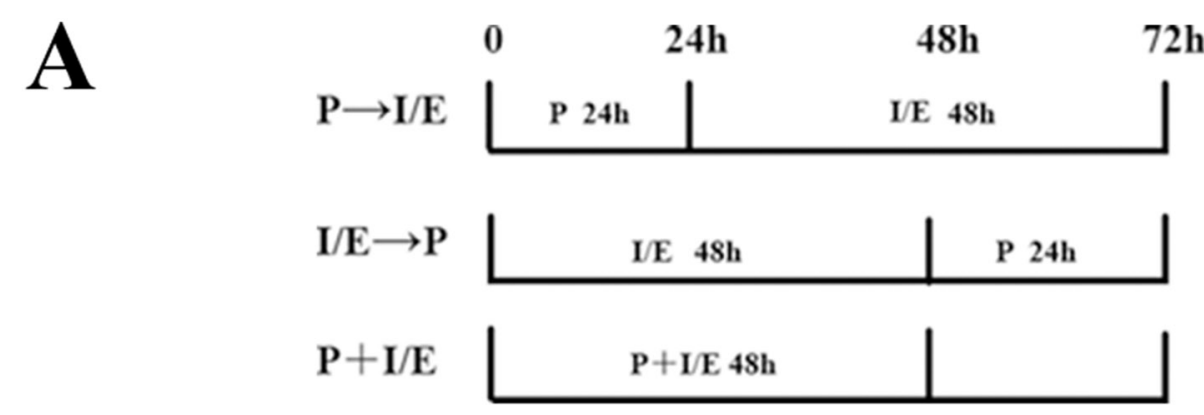

B
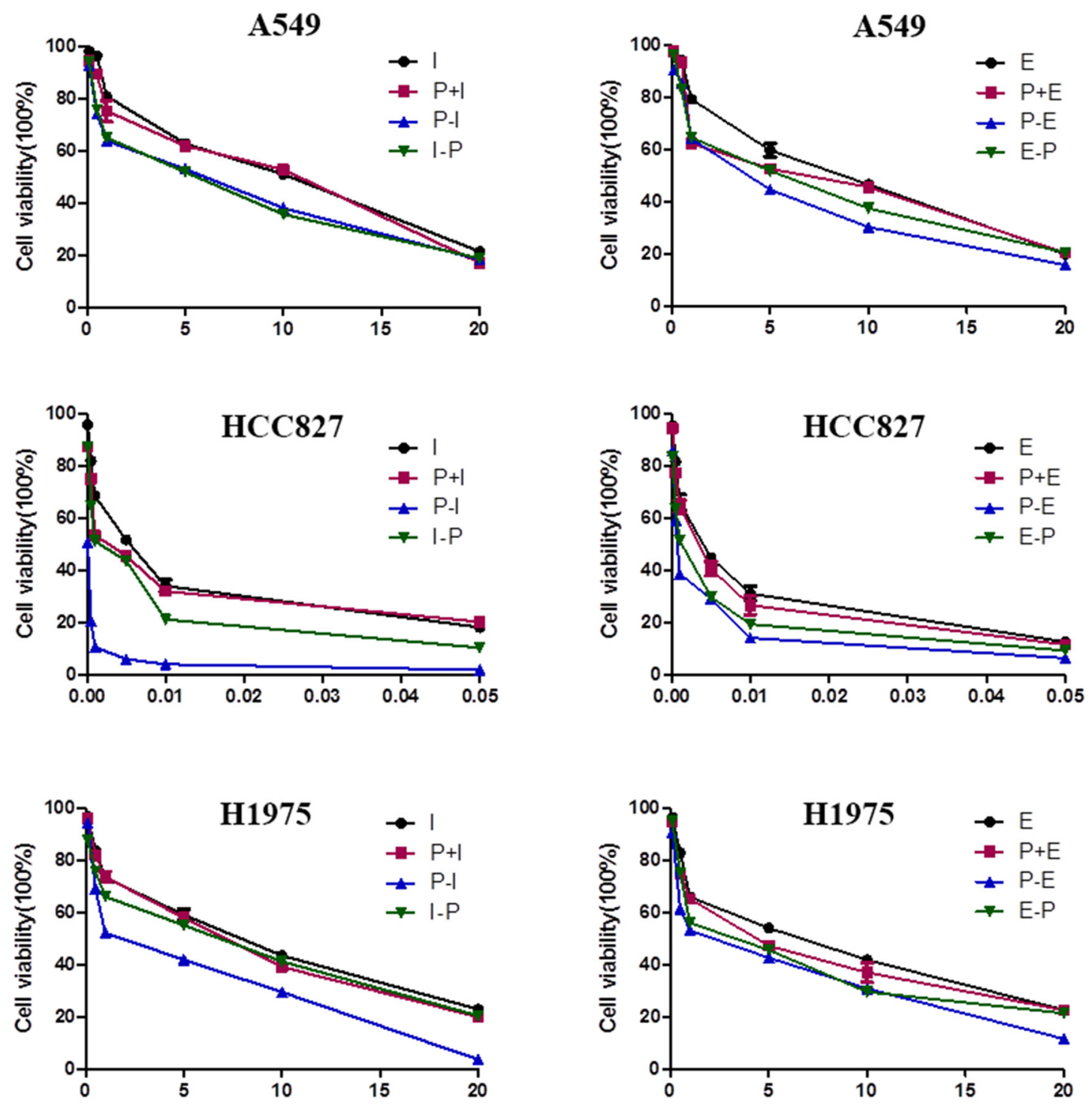

Figure 1: Antiproliferative effects of pemetrexed combined with icotinib/erlotinib are sequence-dependent. (A) Schema of sequential treatment. (B) Sequence of pemetrexed followed by icotinib/erlotinib produced the most potent antiproliferative effect in the lung adenocarcinoma cell lines. P, pemetrexed; I, icotinib; E, erlotinib; P-I/E, pemetrexed followed by icotinib/erlotinib; I/E-P, icotinib/ erlotinib followed by pemetrexed; P-I/E, pemetrexed plus icotinib/erlotinib. Data are presented as the means \pm SD from three independent experiments. 
that a pretreatment with EGFR-TKIs caused G1 arrest and effectively inhibited the activity of chemotherapy, resulting in decreased cytotoxicity and apoptosis [20, 21]. In the present study, single-agent icotinib/erlotinib caused accumulation of cells in G1 phase, while the reduction of G1 phase and enhanced apoptosis were observed in the sequence of pemetrexed followed by icotinib/erlotinib.

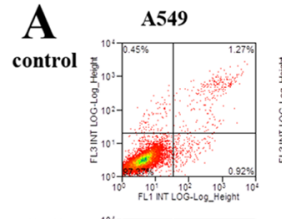

$\mathbf{P + I}$

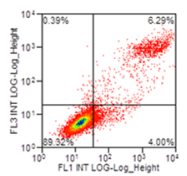

$\mathbf{P} \rightarrow \mathbf{I}$

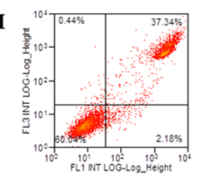

$\mathbf{I} \rightarrow \mathbf{P}$

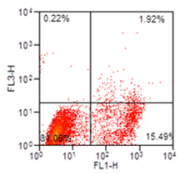

B
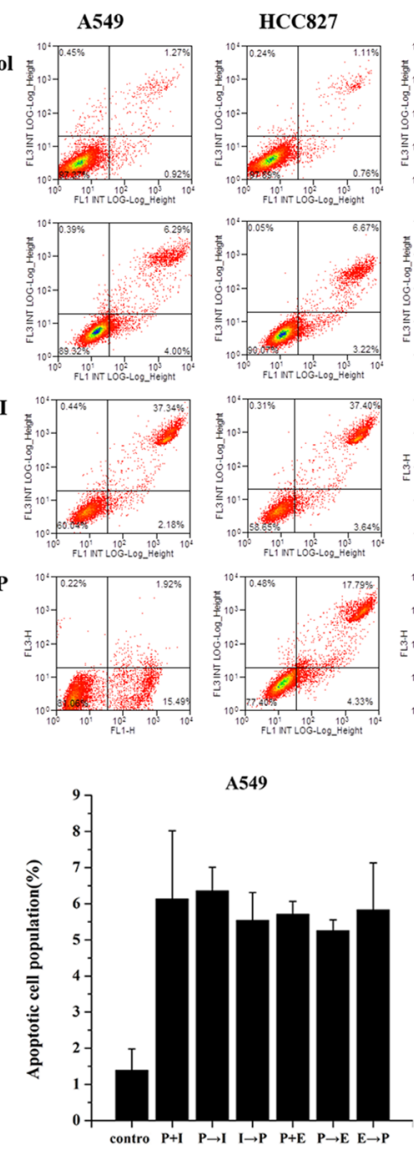
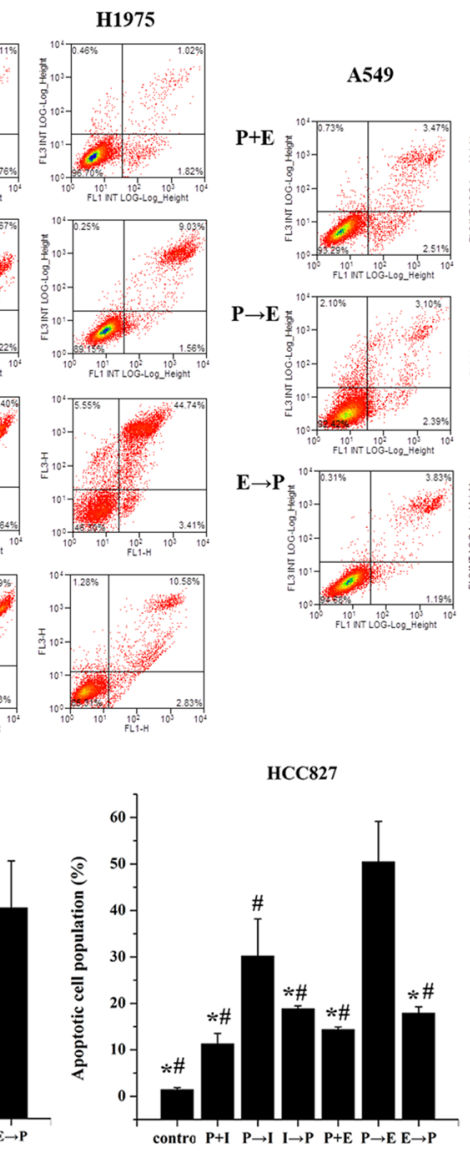
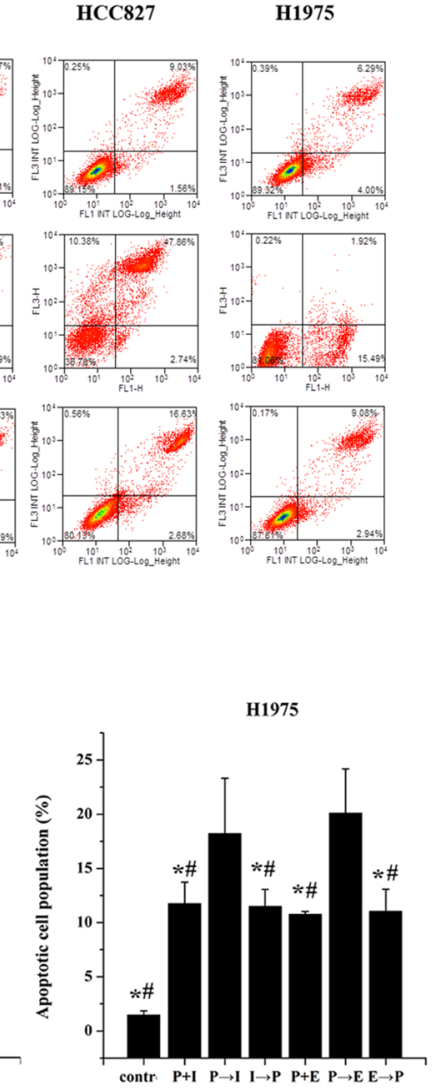

Figure 2: Effects of pemetrexed, icotinib and erlotinib on the cell apoptosis. (A) Cell apoptosis was analyzed by flow cytometry. (B) Apoptotic and necrotic cell population were counted by flow cytometry. Cells were treated with the IC50 value of drugs. P-I/E, pemetrexed followed by icotinib/erlotinib; I/E-P, icotinib/erlotinib followed by pemetrexed; P-I/E, pemetrexed plus icotinib/erlotinib. Data are presented as the means $\pm \mathrm{SD}$ from three independent experiments. Statistically significant differences between $\mathrm{P}-\mathrm{I} / \mathrm{E}$ and other treatment groups are presented as ${ }^{*} P<0.05$.

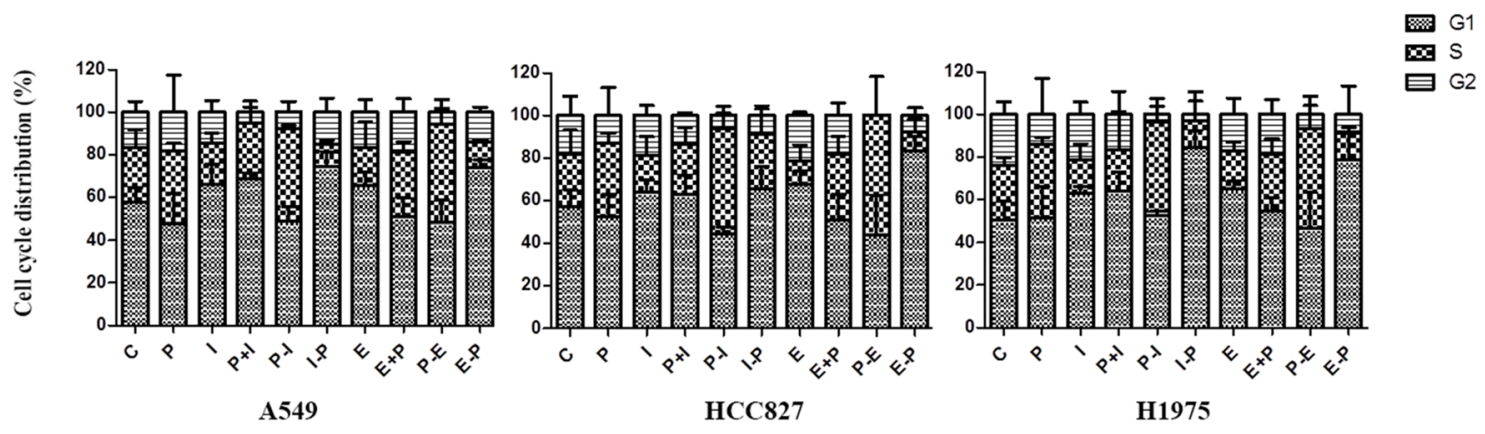

Figure 3: Effects of pemetrexed, icotinib and erlotinib on the cell cycle distribution. Cell cycle distribution was analyzed by flow cytometry. C, control group; P, pemetrexed; I, icotinib; E, erlotinib; P-I/E, pemetrexed followed by icotinib/erlotinib; I/E-P, icotinib/ erlotinib followed by pemetrexed; P-I/E, pemetrexed plus icotinib/erlotinib. Data are presented as the means \pm SD from three independent experiments. 
This study also has some limitations. Preliminarily, the study was only conducted in vitro without further confirmation, thus further evidences are needed to be provided by more in vivo experiments or clinical researches. In addition, more studies still need to enrich the mechanisms underlying the antagonistic interaction of these drugs.

To conclude, the present study revealed that the optimal schedule for lung $\mathrm{AdC}$ treatment in vitro was the sequence of pemetrexed followed by icotinib/erlotinib. These results may provide a rationale and promising strategy for the ongoing clinical investigation of the sequential treatment in patients with lung AdC.

\section{MATERIALS AND METHODS}

\section{Drugs}

Icotinib standard substance (Beida Pharmaceutical co., Zhejiang, China) was configured as $10 \mathrm{mmol} / \mathrm{L}$ solution in dimethyl sulfoxide (DMSO; Sigma, St. Louis, MO, USA). Erlotinib standard substance (Roche pharmaceutical Ltd., Basel, Switzerland) was diluted with DMSO as stocking solution of $100 \mathrm{mmol} / \mathrm{L}$. Pemetrexed (Qilu pharmaceutical company, Jinan, Shandong, China) was dissolved in physiological saline and configured as $10 \mathrm{mmol} / \mathrm{L}$ stocking solution. The solutions were stored at $-20^{\circ} \mathrm{C}$.

\section{Cell lines}

A549, HCC827 and H1975 human lung AdC cell lines were provided by the Chinese academy of medical sciences tumor cells bank (Beijing, China). The cell lines were cultured in RPMI-1640 and DMEM mediums (Gibco, Uxbridge, UK) containing 10\% fetal bovine serum (Gibco, Uxbridge, UK) and $100 \mathrm{U} / \mathrm{ml}$ gentamicin (GIBCO Laboratories Inc., NY, USA) at $37{ }^{\circ} \mathrm{C}$ in a humidified condition containing $5 \% \mathrm{CO}_{2}$. Cells were harvested during the exponential growth phase by trypsin.

\section{Evaluation of cell viability by $\mathrm{CCK}-8$}

The CCK-8 assay (Best Bio, Shanghai, China) was applied to evaluate the cell viability. Cells were implanted $8,000 /$ well in 96 -well plates for $24 \mathrm{~h}$. To evaluate the effects of single medication, the cells were exposed to icotinib, erlotinib or pemetrexed alone for $72 \mathrm{~h}$. To determine the antiproliferative efficacy of the combined treatment, three different sequences were performed as following: 1) Pretreated with icotinib/erlotinib for $48 \mathrm{~h}$ subsequently treated with pemetrexed for $24 \mathrm{~h} ; 2$ ) Preprocessed with pemetrexed for $24 \mathrm{~h}$ followed by icotinib/erlotinib for 48h; 3) Treated icotinib/erlotinib simultaneously with pemetrexed for $48 \mathrm{~h}$, and incubated in drug-free medium for $24 \mathrm{~h}$. After $72 \mathrm{~h}$ drug administration, the cells were incubated with $25 \mu \mathrm{lCCK}-8$ ( $5 \mathrm{mg} / \mathrm{ml})$ after PBS washing at $37^{\circ} \mathrm{C}$ for $4 \mathrm{~h}$. Cell viability was detected at $570 \mathrm{~nm}$. Measurements were carried out on at least 3 different spots. The half maximal inhibitory concentration $\left(\mathrm{IC}_{50}\right)$ was determined at a concentration of $50 \%$ cell growth inhibition compared with the untreated control cells.

\section{Evaluation of apoptosis}

Cells were planted in 6-well plates with a density of $2 \times 10^{5} /$ well. Then cells were trypsinized to analyze the cell apoptosis after the drug administration. $400 \mu \mathrm{l}$ AnnexinV suspension cells were added into the cells and washed with cold PBS. Annexin V-fluorescein isothiocyanate (FITC) and $5 \mu \mathrm{l}$ PI (Joincare Medicine Company, Zhuhai, Guangdong, China) were used for staining for $15 \mathrm{~min}$ at $37^{\circ} \mathrm{C}$ in the dark and analyzed using a FACSCalibur flow cytometer (Becton Dickinson and company, San Jose, CA).

\section{Analysis of cell cycle}

Cells were treated with icotinib, erlotinib and pemetrexed sequentially after culturing with 0.1 FBS for $24 \mathrm{~h}$. Cells were trypsinized, fixed with $70 \%$ ice-cold ethanol for $2 \mathrm{~h}$, then were harvested by centrifugation, washed once with cold PBS, stained with $20 \mu$ Rnase at $37{ }^{\circ} \mathrm{C}$ and $400 \mu \mathrm{l}$ propidium iodide (PI) at $4{ }^{\circ} \mathrm{C}$ for 30 min in dark. Analysis of cell cycle was performed by flow cytometer.

\section{Statistical analysis}

SPSS 19.0 software (SPSS, Chicago, USA) was used to all statistical analysis. Data are expressed as the means \pm SD. The statistical analyses between groups were performed using one-way ANOVA test. The significance level was set at $\alpha=0.05$.

\section{Abbreviations}

EGFR-TKIs, epidermal growth factor receptortyrosine kinase inhibitors; NSCLC, non-small cell lung cancer; CI, Combination index; IC50, half maximal inhibitory concentration; P, pemetrexed; I, icotinib; E, erlotinib; P-I/E, pemetrexed followed by icotinib/erlotinib; $\mathrm{I} / \mathrm{E}-\mathrm{P}$, icotinib/erlotinib followed by pemetrexed; $\mathrm{P}+\mathrm{I} / \mathrm{E}$, pemetrexed plus icotinib/erlotinib

\section{Author contributions}

Yu Li designed the experiments; Xiuli Feng and Yan Zhang carried out experiments and wrote the paper; Tao Li analyzed experimental results. 


\section{ACKNOWLEDGMENTS}

None.

\section{CONFLICTS OF INTEREST}

There is no any potential conflicts of interest.

\section{FUNDING}

This study is supported by Wu Jieping Medical Foundation. NO.: 320.6750.13407.

\section{REFERENCES}

1. Jemal A, Bray F, Center MM, Ferlay J, Ward E, Forman D. Global cancer statistics. CA Cancer J Clin. 2011; 61:69-90.

2. Lortet-Tieulent J, Soerjomataram I, Ferlay J, Rutherford M, Weiderpass E, Bray F. International trends in lung cancer incidence by histological subtype: adenocarcinoma stabilizing in men but still increasing in women. Lung Cancer. 2014; 84:13-22.

3. Rizvi NA, Hellmann MD, Brahmer JR, Juergens RA, Borghaei H, Gettinger S, Chow LQ, Gerber DE, Laurie SA, Goldman JW. Nivolumab in combination with platinumbased doublet chemotherapy for first-line treatment of advanced non-small-cell lung cancer. J Clin Oncol. 2016; 34:2969-2979.

4. Soria JC, Mauguen A, Reck M, Sandler A, Saijo N, Johnson D, Burcoveanu D, Fukuoka M, Besse B, Pignon JP. Systematic review and meta-analysis of randomised, phase II/III trials adding bevacizumab to platinum-based chemotherapy as first-line treatment in patients with advanced non-small-cell lung cancer. Ann Oncol. 2012; 24:20-30.

5. Novello S, Barlesi F, Califano R, Cufer T, Ekman S, Levra MG, Kerr K, Popat S, Reck M, Senan S. Metastatic nonsmall-cell lung cancer: ESMO Clinical Practice Guidelines for diagnosis, treatment and follow-up. Ann Oncol. 2016; 27:v1-v27.

6. Pérez-Moreno MA, Galván-Banqueri M, Flores-Moreno S, Villalba-Moreno Á, Cotrina-Luque J, Bautista-Paloma FJ. Systematic review of efficacy and safety of pemetrexed in non-small-cell-lung cancer. Int J Clin Pharm. 2014; 36:476-487.

7. Cheng Y, Murakami H, Yang PC, He J, Nakagawa K, Kang JH, Kim JH, Wang X, Enatsu S, Puri T. Randomized phase II trial of gefitinib with and without pemetrexed as first-line therapy in patients with advanced nonsquamous non-smallcell lung cancer with activating epidermal growth factor receptor mutations. J Clin Oncol. 2016; 34:3258-3266.

8. Yoshimura N, Kudoh S, Mitsuoka S, Yoshimoto N, Oka T, Nakai T, Suzumira T, Matusura K, Tochino Y, Asai K. Phase II study of a combination regimen of gefitinib and pemetrexed as first-line treatment in patients with advanced non-small cell lung cancer harboring a sensitive EGFR mutation. Lung Cancer. 2015; 90:65-70.

9. Cheng H, An SJ, Dong S, Zhang YF, Zhang XC, Chen ZH, $\mathrm{Wu}$ YL. Molecular mechanism of the schedule-dependent synergistic interaction in EGFR-mutant non-small cell lung cancer cell lines treated with paclitaxel and gefitinib. J Hematol Oncol. 2011; 4:5.

10. Mok TS, Wu YL, Yu CJ, Zhou C, Chen YM, Zhang $\mathrm{L}$, Ignacio J, Liao $\mathrm{M}$, Srimuninnimit $\mathrm{V}$, Boyer MJ. Randomized, placebo-controlled, phase II study of sequential erlotinib and chemotherapy as first-line treatment for advanced non-small-cell lung cancer. J Clin Oncol. 2009; 27:5080-5087.

11. Laurila N, Koivunen JP. EGFR inhibitor and chemotherapy combinations for acquired TKI resistance in EGFR-mutant NSCLC models. Med Oncol. 2015; 32:1.

12. Goss GD, Spaans JN. Epidermal growth factor receptor inhibition in the management of squamous cell carcinoma of the lung. Oncologist. 2016; 21:205-213.

13. Fiala O, Pesek M, Finek J, Benesova L, Bortlicek Z, Minarik M. Sequential treatment of advanced-stage lung adenocarcinoma harboring wild-type EGFR gene: secondline pemetrexed followed by third-line Erlotinib versus the reverse sequence. Anticancer Res. 2013; 33:3397-3402.

14. Zheng Y, Fang W, Deng J, Zhao P, Xu N, Zhou J. Sequential treatment of icotinib after first-line pemetrexed in advanced lung adenocarcinoma with unknown EGFR gene status. J Thorac Dis. 2014; 6:958-964.

15. Fukuoka M, Wu YL, Thongprasert S, Sunpaweravong P, Leong SS, Sriuranpong V, Chao TY, Nakagawa K, Chu DT, Saijo N. Biomarker analyses and final overall survival results from a phase III, randomized, open-label, first-line study of gefitinib versus carboplatin/paclitaxel in clinically selected patients with advanced non-small-cell lung cancer in Asia (IPASS). J Clin Oncol. 2011; 29:2866-2874.

16. Zhou C, Wu YL, Chen G, Feng J, Liu XQ, Wang C, Zhang S, Wang J, Zhou S, Ren S. Erlotinib versus chemotherapy as first-line treatment for patients with advanced EGFR mutation-positive non-small-cell lung cancer (OPTIMAL, CTONG-0802): a multicentre, open-label, randomised, phase 3 study. Lancet Oncol. 2011; 12:735-742.

17. Wu YL, Lee JS, Thongprasert S, Yu CJ, Zhang L, Ladrera G, Srimuninnimit V, Sriuranpong V, Sandoval-Tan J, Zhu Y. Intercalated combination of chemotherapy and erlotinib for patients with advanced stage non-small-cell lung cancer (FASTACT-2): a randomised, double-blind trial. Lancet Oncol. 2013; 14:777-786.

18. Yan H, Li H, Li Q, Zhao P, Wang W, Cao B. The efficacy of synchronous combination of chemotherapy and EGFR TKIs for the first-line treatment of NSCLC: a systematic analysis. PLoS One. 2015; 10:e0135829.

19. Mahaffey CM, Davies AM, Lara JPN, Pryde B, Holland W, Mack PC, Gumerlock PH, Gandara DR. Scheduledependent apoptosis in K-ras mutant non-small-cell lung 
cancer cell lines treated with docetaxel and erlotinib: rationale for pharmacodynamic separation. Clin Lung Cancer. 2007; 8:548-553.

20. Cheng H, An SJ, Zhang XC, Dong S, Zhang YF, Chen ZH, Chen HJ, Guo AL, Lin QX, Wu YL. In vitro sequencedependent synergism between paclitaxel and gefitinib in human lung cancer cell lines. Cancer Chemother Pharmacol. 2011; 67:637-646.
21. Wu M, Yuan Y, Pan YY, Zhang Y. Antitumor activity of combination treatment with gefitinib and docetaxel in EGFR-TKI-sensitive, primary resistant and acquired resistant human non-small cell lung cancer cells. Mol Med Rep. 2014; 9:2417-2422. 